\title{
Optimalisasi Metode LPC-16 dan HMM-Forward Pada Sistem Asisten Virtual
}

\author{
Chondro Seto Nur Suryawan, Marisa Premitasari \\ Institut Teknologi Nasional \\ Jl. PH.H. Mustofa No.23 Bandung 40124, Bandung \\ chondroseto@windowslive.com, marisa.premitasari@gmail
}

\begin{abstract}
Abstrak
Pada umumnya manusia saat ini menggunakan sistem operasi windows yang berjalan di perangkat desktop akan memasang banyak aplikasi sesuai kebutuhannya. Semakin banyak aplikasi yang di pasang maka semakin banyak pula shortcut yang tampil di bagian desktop windows. Shortcut sendiri merupakan sebuah objek alternatif yang digunakan untuk mewakili sehingga pengguna dapat dengan mudah membuka aplikasi tanpa harus pengguna membuka tempat dimana aplikasi tersebut terpasang. Banyaknya aplikasi yang terpasang pada sistem operasi windows membuat shortcut pada bagian desktop menjadi banyak dan membuat pengguna kesulitan dalam mencari atau membuka aplikasi yang dinginkan. Oleh karena itu diperlukan aplikasi yang dapat membantu pengguna dalam mencari dan membuka aplikasi dengan mudah tanpa membuat pengguna kesulitan. Aplikasi tersebut adalah virtual asisten yang akan membantu pengguna dalam mencari dan membuka aplikasi yang diinginkan. Cara kerjanya dengan pengguna memasukan suara pengguna lalu di proses ekstraksi ciri menggunakan metode Linear Predictive Coding lalu di klasifikasikan menggunakan metode Hidden Markov Model Forward. Setelah terdeteksi maka aplikasi akan membuka aplikasi sesuai suara yang terdeksi. Penelitian ini menggunakan 120 data latih yang terdiri dari 6 label yaitu whatsapp, linkedin, Tokopedia, gmail, powerpoint, word. Untuk setiap label memiliki data latih berjumlah 20 data. Data yang diujikan berjumlah 60 . Untuk setiap labelnya memiliki 10 data uji.
\end{abstract}

Kata kunci :

Pengenalan Suara, Linear Predictive Coding, Hidden Markov Model

\begin{abstract}
In general, people today using windows operating system that runs on desktop devices will install many applications as needed. The more applications installed, the more shortcuts that appear in the desktop part of windows. Shortcut itself is an alternative object used to represent so that the user can easily open the application. Users can open without having to open the place where the application is installed. The large number of applications installed on the windows operating system makes shortcuts on the desktop become many and makes it difficult for users to find or open cool applications. Therefore, an application is needed that can assist the user in finding and opening the application easily without making it difficult for the user. The app is a virtual assistant that will assist users in finding and opening the desired application. How it works with the user entering the user's voice and then in the process of extracting the characteristics using the Linear Predictive Coding method and then classified using the Hidden Markov Model Forward method. Once detected, the application will open the application according to the detected sound. This study used 120 training data that were divided into 6 labels consisting of Whatsapp, Linkedin, Tokopedia, Gmail, PowerPoint, and Word. For each label has a training data of 20 data. The data tested amounted to 60. Each label has 10 test data.
\end{abstract}

Keywords :

Speech Recognition, Linear Predictive Coding, Hidden Markov Model 


\section{Pendahuluan}

Pada Umumnya manusia saat ini menggunakan sistem operasi windows yang dapat berjalan di perangkat dekstop akan memasang banyak aplikasi karena banyaknya kebutuhan sehingga pada bagian dekstop terdapat banyak aplikasi yang terlihat Umumnya pengguna memasang banyak aplikasi di sistem operasi windowsnya karena digunakan untuk bekerja dan keseharian serta hiburan. pengguna dapat membuka aplikasi dengan shortcut aplikasi pada bagian desktop di sistem operasi windows. Dalam mencari shorcut aplikasi membutuhkan waktu yang tidak sedikit terkadang pengguna keliru dan salah klik aplikasi sehingga membuat pusing pengguna. Dilihat dari proses pencarian aplikasi yang cukup panjang tersebut maka diperlukan suatu solusi yang dapat menyederhanakan suatu proses tersebut untuk membuka aplikasi tanpa harus mencari menggunakan penglihatan pengguna. Solusi yang diperlukan adalah sebuah aplikasi yang dapat membuka hanya dengan menyebutkan nama aplikasinya saja menggunakan suara pengguna tanpa perlu mencari aplikasi dengan penglihatan pengguna

Aplikasi ini memerlukan masukan pengguna berupa suara pengguna yang menyebutkan nama aplikasi tersebut lalu di proses dengan mengubahnya menjadi angka digital. Angka digital tersebut lalu di klasifikasikan sesuai dengan data yang sudah di latih sebelumnya. Setelah terdeteksi maka akan tampil teks atau nama aplikasi yang hasil proses pengenalan suara tersebut. Setelah itu sistem akan mencari sesuai hasil pengenalan suara tersebut dan mencocokannya dengan aplikasi yang sesuai yang sudah tersedia pada aplikasi tersebut. Jika hasil klasifikasi terdapat kecocokan dengan nama aplikasi yang sudah terdaftar maka aplikasi akan dibuka oleh aplikasi dan di jalan kan oleh sistem operasi. Nama aplikasi ini biasanya disebut virtual asisten

Virtual asisten adalah sebuah agen yang cerdas yang memiliki tujuan untuk membantu pengguna dalam melakukan suatu tugas. Umumnya virtual asisten menggunakan masukan suara dari pengguna untuk melakukan suatu tugas. Dalam mengenali pengguna dan melakukan tugas diperlukan pengenalan terlebih dahulu dengan suara pengguna.

Pengenalan suara adalah suatu proses dalam mengenali suatu suara. Dalam mengenali suara, suara harus di ekstraksi terlebih dahulu . dalam penelitian ini penulis menggunakan metode Linear Predictive
Coding untuk mengekstraksi suara. Bukan hanya ekstraksi ciri tapi juga diperlukan metode lain untuk mengenali hasil dari ekstraksi ciri. Dalam penelitian ini juga menggunakan metode Hidden Markov Model.

Linear Predictive Coding merupakan metode ekstraksi dari sinyal suara menjadi bentuk nilai-nilai berupa koefisien Linear Predictive Coding. Biasanya metode ini digunakan untuk speech recognition, speech to text dan text to speech.

Hidden Markov Model merupakan sebuah model statistik dari suatu sistem yang dapat menghitung probabilitas dari suatu kejadian yang tidak dapat observasi berdasarkan kejadian yang dapat observasi. Hidden Markov Model terdiri dari 4 Algoritma yang terdiri dari Forward, Backward, Viterbi dan Baum Welch. Algoritma yang digunakan adalah algoritma forward. Algoritma ini akan digunakan pada saat proses pencocokan dengan data latih.

Penelitian mengenai pengenalan suara sudah dilakukan oleh (Abdullah, \& Ramadhan, 2016) yang berjudul Implementasi Algoritma Hidden Markov Model Sebagai Pengenalan Perintah Suara Pada Aplikasi Winamp yang meneliti tentang pengenalan perintah suara menggunkan metode linear predictive coding dan hidden markov model, untuk parameter linear predictive coding yang digunakan dalam penelitian ini tidak disebutkan dan algoritma yang digunakan pada hidden markov model juga tidak disebutkan.

Oleh karena itu penelitian penulis akan meneliti metode linear predictive coding dengan ordo 16 dan hidden markov model dengan algoritma forward dalam mengenali suara.diharapkan dengan metode linear predictive coding dengan ordo16 akurasi dapat mencapai angka $80 \%$.

\section{LANDASAN TEORI}

\section{II.1 Virtual Asisten}

Virtual Asisten adalah suatu agen cerdas dimana agen ini memiliki tujuan untuk membantu melakukan tugas dengan menyederhanakan suatu kegiatan dengan perintah suara (Massai, Nesi, \& Pantaleo, 2019).

Teknologi ini berfungsi untuk memudahkan pengguna dalam melakukan suatu hal yang biasanya di lakukan oleh pengguna, dimana pengguna hanya perlu memanggil apa yang diinginkan lalu virtual asisten akan melakukan apa yang diinginkan 
pengguna atau mewakili pengguna dalam melakukan hal tersebut

Virtual asisten ini juga dikenal dengan virtual personal assistant (VPA). Contoh virtual asisten yaitu Google Assistant, Microsoft Cortana, Apple Siri dan Amazon Alexa.

\section{II.2 Pengenalan Suara}

Pengenalan Suara (Speech Recognition) adalah suatu proses dalam mengenali kata yang diucapkan oleh komputer (Abdullah, \& Ramadhan, 2016). Input yang diperlukan dari pengenalan suara ialah berupa suara atau ucapan yang diubah menjadi sinyal digital dengan cara mengubah gelombang suara menjadi sekumpulan angka lalu disesuaikan dengan kode dan pola yang tersimpan di dalam suatu perangkat. Setiap ucapan memiliki pola ciri yang berbeda

Terdapat dua tipe pengenalan suara (speech recognition) berdasarkan ketergantungan pembicara yaitu independent speech recognition dan dependent speech recognition.

Independent speech recognition adalah sistem pengenalan ucapan yang tidak dipengaruhi oleh pembicara, tetapi mempunyai keterbatasan dalam jumlah kata. Contohnya asisten virtual Microsoft cortana, apple siri dan google assistant

Dependent speech recognition adalah sistem pengenalan ucapan yang dipengaruhi oleh pembicara. Sistem ini memerlukan pelatihan khusus dari pembicara dimana Hasil pelatihan dari setiap pembicara akan di simpan pada kelas. kelas inilah yang akan digunakan pada sistem untuk mengenali pembicara untuk berinteraksi dengan sisitem. Contohnya pada sistem untuk membuka kunci dengan suara

\section{II.3 Linear Predictive Coding}

LPC (Linear Predictive Coding) adalah suatu metode ekstraksi ciri dari sinyal suara yang dapat mengubah ciri dari suatu sinyal menjadi ke dalam bentuk nilai berupa koefisien Linear Predictive Coding atau LPC (Abdullah, \& Ramadhan, 2016). Metode Linear Predictive Coding lebih sering digunakan pada aplikasi yang speech recognition, speech to text dan text to speech. Proses linear predictive coding membutuhkan beberapa parameter yaitu :

$\mathrm{N}=$ jumlah sample per frame
$\mathrm{M}=$ jarak antara frame yang berurutan $\mathrm{P}=$ ordo LPC

Dalam proses ekstraksi ciri menggunakan metode Linear Predictive Coding terdapat 6 tahapan yang ditunjukan pada Gambar 2.1 berikut ini :

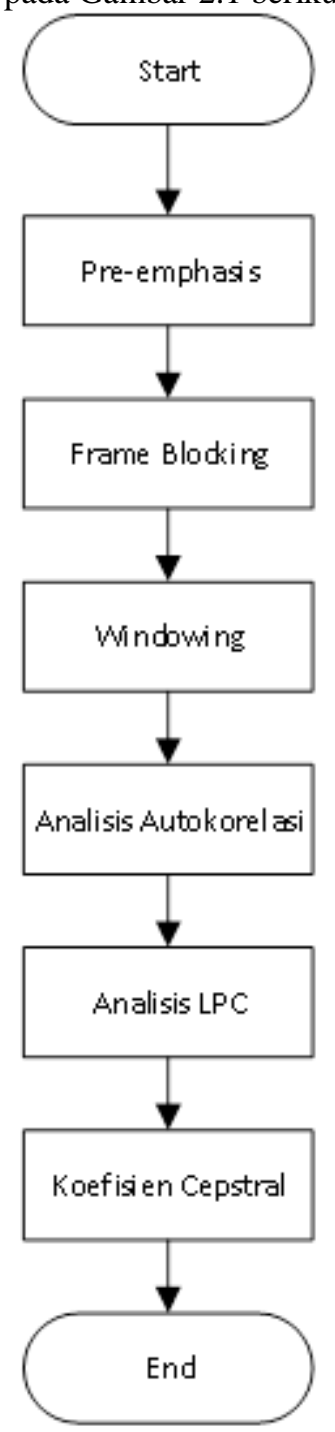

Gambar 1 Flowchart Metode LPC

\section{II.4 Hidden Markov Model}

HMM (Hidden Markov Model) merupakan sebuah model statistik dari suatu sistem yang dapat melakukan perhitungan probabilitas dari suatu kejadian yang tidak dapat di observasi berdasarkan kejadian yang dapat di observasi (Widhiyantil, 2012).

Chondro Seto Nur Suryawan, Marisa Premitasari 
Hidden Markov Model memiliki 2 macam bagian yaitu observed state dan hidden state. Observed state adalah bagian yang dapat diamati sedangkan hidden state adalah bagian yang tidak dapat diamati (Widhiyantil, 2012)

Metode hidden markov model dapat digunakan untuk aplikasi di bidang pattern recognition contohnya pengenalan suara, pengenalan tulisan, pengenalan gestur, bioinformatika, kompresi kalimat, computer vision, dan lain-lain

Hidden Markov Model memiliki 4 algoritma yaitu Forward, Backward, Viterbi dan Baum Welch. Algoritma yang digunakan pada penelitian ini adalah algoritma forward yang akan digunakaan saat proses pencocokan dengan data hasil training.

Hidden Markov Model menggabungkan dua atau lebih rantai markov dimana satu rantai yang terdiri dari state yang dapat diobservasi dan rantai lainnya membentuk state yang tidak dapat diobservasi, yang akan mempengaruhi hasil state yang dapat diobservasi.

Pada penelitian ini digunakan algoritma yang digunakan adalah algoritma forward yang teridiri dari 3 tahapan yang ditunjukan pada Gambar 2 berikut.

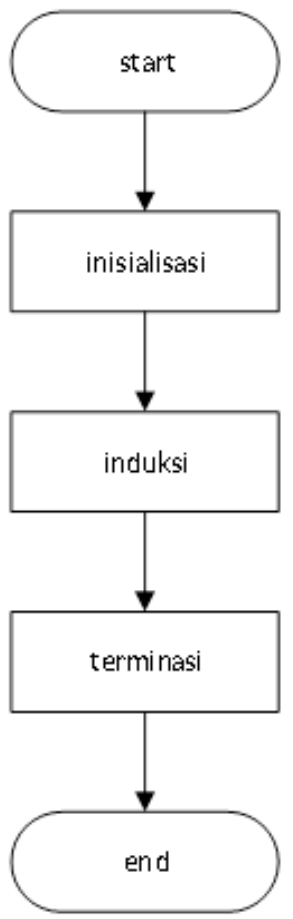

Gambar 2 Flowchart Metode HMM

\section{ANALISIS DAN PERANCANGAN}

\section{III.1 Blok Diagram}

Dibawah ini adalah blok diagram sistem ditunjukan pada Gambar 3 berikut ini.

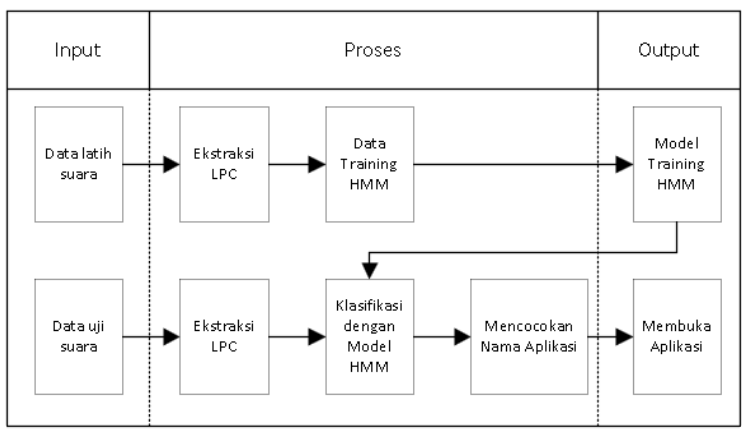

Gambar 3 Blok Diagram Sistem

Berdasarkan gambar blok diagram diatas ini, terdapat dua proses yaitu proses data latih suara dan data suara uji. Untuk proses data latih suara, data latih suara akan di ekstraksi dengan metode Linear Predictive Coding lalu di latih menjadi data training. Sedangkan untuk data suara uji akan di ekstraksi Linear Predictive Coding lalu hasil data training akan di masukan ke klasifikasi Hidden Markov Model setelah itu akan memulai proses mencocokan nama aplikasi. Hasil outputnya akan tampil teks hasil input suara dan membuka aplikasi yang dituju.

\section{III.2 Pengambilan Data}

Data latih suara dan data uji suara menggunakan suara penulis. Format file data suara yang digunakan untuk data latih suara dan data uji suara adalah format data WAV(Waveform Audio File). Sample rate yang digunakan untuk data latih suara dan data uji suara adalah 8000 sample rate. data latih suara dan data uji suara berdurasi dua detik lebih dan tidak lebih dari tiga detik.

Data latih suara diperoleh dari suara penulis dengan jumlah total 120 data suara yang terdiri dari enam label. Masing-masing label berisi 20 data suara. Data uji suara diperoleh dari suara penulis dengan jumlah total 60 data suara yang terdiri dari enam label. Masing-masing label berisi 10 data suara. Label terdiri dari Gmail, Whatsapp, Tokopedia, LinkedIn, Word dan Powerpoint. Setiap label memiliki data latih suara dan data uji suara. 


\section{III.3 Hasil Pengujian}

Dibawah ini hasil pengujian data yang ditunjukan pada Tabel 4.7 berikut ini

\section{Tabel 1 Hasil Pengujian Data}

\begin{tabular}{|c|c|c|}
\hline File Suara & $\begin{array}{c}\text { Label } \\
\text { Sebenarnya }\end{array}$ & $\begin{array}{c}\text { Label Hasil } \\
\text { Prediksi }\end{array}$ \\
\hline Whatsappuji1.wav & Whatsapp & Whatsapp \\
\hline Whatsappuji2.wav & Whatsapp & Whatsapp \\
\hline Whatsappuji3.wav & Whatsapp & Whatsapp \\
\hline Whatsappuji4.wav & Whatsapp & Whatsapp \\
\hline Whatsappuji5.wav & Whatsapp & Whatsapp \\
\hline Whatsappuji6.wav & Whatsapp & Tokopedia \\
\hline Whatsappuji7.wav & Whatsapp & Whatsapp \\
\hline Whatsappuji8.wav & Whatsapp & Whatsapp \\
\hline Whatsappuji9.wav & Whatsapp & Whatsapp \\
\hline Whatsappuji10.wav & Whatsapp & Tokopedia \\
\hline Linkedinuji1.wav & Linkedin & Linkedin \\
\hline Linkedinuji2.wav & Linkedin & Linkedin \\
\hline Linkedinuji3wav & Linkedin & Linkedin \\
\hline Linkedinuji4.wav & Linkedin & Linkedin \\
\hline Linkedinuji5.wav & Linkedin & Linkedin \\
\hline Linkedinuji6.wav & Linkedin & Linkedin \\
\hline Linkedinuji7.wav & Linkedin & Linkedin \\
\hline Linkedinuji8.wav & Linkedin & Linkedin \\
\hline Linkedinuji9.wav & Linkedin & Tokopedia \\
\hline
\end{tabular}

\begin{tabular}{|c|c|c|}
\hline Linkedinuji10.wav & Linkedin & Linkedin \\
\hline Tokopediauji1.wav & Tokopedia & Tokopedia \\
\hline Tokopediauji2.wav & Tokopedia & Tokopedia \\
\hline Tokopediauji3.wav & Tokopedia & Tokopedia \\
\hline Tokopediauji4.wav & Tokopedia & Tokopedia \\
\hline Tokopediauji5.wav & Tokopedia & Tokopedia \\
\hline Tokopediauji6.wav & Tokopedia & Tokopedia \\
\hline Tokopediauji7.wav & Tokopedia & Tokopedia \\
\hline Tokopediauji8.wav & Tokopedia & Whatsapp \\
\hline Tokopediauji9.wav & Tokopedia & Tokopedia \\
\hline Tokopediauji10.wav & Tokopedia & Whatsapp \\
\hline Gmailuji1.wav & Gmail & Tokopedia \\
\hline Gmailuji2.wav & Gmail & Gmail \\
\hline Gmailuji3.wav & Gmail & Gmail \\
\hline Gmailuji4.wav & Gmail & Tokopedia \\
\hline Gmailuji5.wav & Gmail & Gmail \\
\hline Gmailuji6.wav & Gmail & Gmail \\
\hline Gmailuji7.wav & Gmail & Gmail \\
\hline Gmailuji8.wav & Gmail & Gmail \\
\hline Gmailuji9.wav & Gmail & Gmail \\
\hline Gmailuji10.wav & Gmail & Gmail \\
\hline Powerpointuji1.wav & Powerpoint & Powerpoint \\
\hline Powerpointuji2.wav & Powerpoint & Powerpoint \\
\hline Powerpointuji3.wav & Powerpoint & Powerpoint \\
\hline
\end{tabular}

Chondro Seto Nur Suryawan, Marisa Premitasari 


\begin{tabular}{|c|c|c|}
\hline Powerpointuji4.wav & Powerpoint & Powerpoint \\
\hline Powerpointuji5.wav & Powerpoint & Powerpoint \\
\hline Powerpointuji6.wav & Powerpoint & Powerpoint \\
\hline Powerpointuji7.wav & Powerpoint & Powerpoint \\
\hline Powerpointuji8.wav & Powerpoint & Powerpoint \\
\hline Powerpointuji9.wav & Powerpoint & Word \\
\hline Powerpointuji10.wav & Powerpoint & Powerpoint \\
\hline Wordujil.wav & Word & Word \\
\hline Worduji2.wav & Word & Word \\
\hline Worduji3.wav & Word & Word \\
\hline Worduji4.wav & Word & Word \\
\hline Worduji5.wav & Word & Word \\
\hline Worduji6.wav & Word & Word \\
\hline Worduji7.wav & Word & Word \\
\hline Worduji8.wav & Word & Tokopedia \\
\hline Worduji9.wav & Word & Word \\
\hline Worduji10.wav & Word & Word \\
\hline
\end{tabular}

\begin{tabular}{|c|c|c|c|c|}
\hline 3 & Tokopedia & 8 & 2 & $80 \%$ \\
\hline 4 & Gmail & 8 & 2 & $80 \%$ \\
\hline 5 & Powerpoint & 9 & 1 & $90 \%$ \\
\hline 6 & Word & 9 & 1 & $90 \%$ \\
\hline
\end{tabular}

Berdasarkan tabel di atas whatsapp memiliki persentase $80 \%$ yang terdeteksi dari 10 suara uji. Linkedin memiliki persentase $90 \%$ yang terdeteksi dari 10 suara uji. Tokopedia memiliki persentase $80 \%$ yang terdeteksi dari 10 suara uji. Gmail memiliki persentase $80 \%$ yang terdeteksi dari 10 suara uji. Powerpoint memiliki persentase $90 \%$ yang terdeteksi dari 10 suara uji. Word memiliki persentase $90 \%$ yang terdeteksi dari 10 suara uji.

Tabel 4.9 Hasil Pengujian Berdasarkan Ordo LPC

\begin{tabular}{|c|c|c|c|c|c|c|}
\hline \multirow{2}{*}{ No } & \multirow{2}{*}{$\begin{array}{c}\text { Nama } \\
\text { Aplikasi }\end{array}$} & \multicolumn{5}{|c|}{ Ordo LPC } \\
\cline { 3 - 7 } & & 16 & 15 & 14 & 13 & 12 \\
\hline 1 & Whatsapp & $80 \%$ & $80 \%$ & $60 \%$ & $50 \%$ & $20 \%$ \\
\hline 2 & Linkedin & $90 \%$ & $90 \%$ & $80 \%$ & $80 \%$ & $50 \%$ \\
\hline 3 & Tokopedia & $80 \%$ & $80 \%$ & $60 \%$ & $50 \%$ & $70 \%$ \\
\hline 4 & Gmail & $80 \%$ & $60 \%$ & $50 \%$ & $70 \%$ & $50 \%$ \\
\hline 5 & Powerpoint & $90 \%$ & $90 \%$ & $90 \%$ & $100 \%$ & $100 \%$ \\
\hline 6 & Word & $90 \%$ & $80 \%$ & $80 \%$ & $70 \%$ & $50 \%$ \\
\hline \multicolumn{2}{|c|}{ Rata-Rata } & $85 \%$ & $80 \%$ & $70 \%$ & $70 \%$ & $57 \%$ \\
\hline
\end{tabular}

\begin{tabular}{|c|c|c|c|c|}
\hline No. & $\begin{array}{c}\text { Nama } \\
\text { Aplikasi }\end{array}$ & Terdeteksi & $\begin{array}{c}\text { Tidak } \\
\text { Terdeteksi }\end{array}$ & Persentase \\
\hline 1 & Whatsapp & 8 & 2 & $80 \%$ \\
\hline 2 & Linkedin & 9 & 1 & $90 \%$ \\
\hline
\end{tabular}

Berdasarkan data tabel hasil pengujian diatas didapatkan hasil berupa nilai rata-rata persentase pengujian deteksi. pengujian dengan ordo 16 memiliki rata-rata persentase $85 \%$. pengujian dengan ordo 15 memiliki rata-rata persentase $80 \%$. pengujian dengan ordo 14 memiliki rata-rata persentase $70 \%$. pengujian dengan ordo 13 memiliki rata-rata persentase $70 \%$. pengujian dengan ordo 12 memiliki rata-rata

Chondro Seto Nur Suryawan, Marisa Premitasari 
persentase 57\%. Pengujian dengan ordo 16 memiliki persentase terbesar daripada pengujian dengan ordo yang diujikan.

\section{KESIMPULAN DAN SARAN}

Berdasarkan hasil pengujian data suara dari 6 nama aplikasi yang terdiri dari Whatsapp, Linkedin, Tokopedia, Gmail, Powerpoint, Word yang menggunakan metode Linear Predictive Coding dengan ordo 16 dan menggunakan metode Hidden Markov Model Forward menghasilkan persentase rata-rata dalam mendeteksi data suara adalah $85 \%$ serta memiliki nilai rata-rata tertinggi diantara pengujian ordo Linear Predictive Coding 15, 14,13, dan 12. Sehingga ordo 16 adalah ordo Linear Predictive Coding yang paling optimal berdasarkan rata-rata deteksi tertinggi.

Keakurasian deteksi ini juga di pengaruhi oleh banyak faktor yang bisa menyebabkan keberagaman hasil akurasi diantaranya data latih, data uji dan nilai ordo yang digunakan pada metode Linear predictive coding serta Algoritma Hidden Markov Model

\section{REFERENSI}

Champion, C., \& Houghton, S. M. (2015). Application of continuous state Hidden Markov Models to a classical problem in speech recognition. ComputerSpeech \& Language,1-18.

https://doi.org/10.1016/j.csl.2015.05.001

DEWI, I. A., ZULKARNAIN, A., \& LESTARI, A. A. (2018). Identifikasi Suara Tangisan Bayi menggunakan Metode LPC dan Euclidean Distance. ELKOMIKA: Jurnal Teknik Energi Elektrik, Teknik Telekomunikasi, \& Teknik Elektronika,6(1),153. https://doi.org/10.26760/elkomika.v6i1. 153

Khairunizam, Danuri, \& Jaroji. (2017). Aplikasi Pemutar Musik Menggunakan Speech Recognition. 2(2).

Khandade, S., \& Khot, S. (2016). Speaker Recognition Based Home Automation Using Matlab. (9), 1627-1631.

Massai, L., Nesi, P., \& Pantaleo, G. (2019). PAVAL: A location-aware virtual personal assistant for retrieving geolocated points of interest and location-based services. Engineering
Applications of Artificial Intelligence, 77(September 2018), 70-85. https://doi.org/10.1016/j.engappai.2018. 09.013

Mouaza, B., Abderrahim, B. H., \& Abdelmajid, E. (2019). ScienceDirect ScienceDirect Speech Recognition of Dialect Using Hidden Markov 29 Moroccan Models Speech Recognition of Moroccan Dialect Using Hidden Markov. Procedia Computer Science, 151(2018), 985-991. https://doi. org/10.1016/j.procs.2019.04.138

Nada, Q., Ridhuandi, C., Santoso, P., \& Apriyanto, D. (2019). Speech Recognition dengan Hidden Markov Model untuk. 5(1), 19-26.

Orosanu, L., \& Jouvet, D. (2018). Detection of sentence modality on French automatic speech-to-text transcriptions. Procedia Computer Science, 128, 38-46. https://doi.org/10.1016/j.procs.2018.03. 006

Pseudocode, J., Abdullah, D., \& Ramadhan, R. (2016). IMPLEMENTASI ALGORITMA HIDDEN MARKOV MODEL SEBAGAI PENGENALAN. III, 15-25.

Shadiev, R., \& Huang, Y. M. (2016). Facilitating cross-cultural understanding with learning activities supported by speech-totext recognition and computer-aided translation. Computers and Education, 98, 130-141. https://doi.org/10.1016/j.compedu.2016. 03.013

Sharma, S., Kumar, V., \& Rana, K. P. S. (2019). Automatic oscillations detection and quantification in process control loops using linear predictive coding. Engineering Science and Technology, an International Journal, (xxxx).https://doi.org/10.1016/j.jestch.20 19.04.006

Widhiyantil, K. (2012). Dengan HMM dan Rule Based. 8(2).

Chondro Seto Nur Suryawan, Marisa Premitasari 